\title{
Hypothyroidism and platelet parameter evaluation: a preliminary study
}

Scavuzzo F. $\left(^{*}\right)$, Genna M.L. $\left({ }^{* *}\right)$, Nastri G. $\left({ }^{* *}\right)$, Serino D. $\left({ }^{*}\right)$, Volpe R. $\left({ }^{*}\right)$

(*) Endocrinology Unit, (**) Department of Laboratory Medicine - Azienda Ospedaliera di Rilievo Nazionale - Hospital Antonio Cardarelli, Naples (Italy)

\section{OBJECTIVES}

According to the findings of recent epidemiological research, thyroid complaints are among the most frequent endocrine illnesses in Italy. Being positively correlated to MPV, the mean platelet volume, in subjects with hypothyroidism, it has been hypothesized in literature that TSH can have a probable prothrombotic effect. MPV (Mean Platelet Volume), PCT (Plateletcrit), PDW (Platelet Distribution Width) and P-LCR (Platelet-Large Cell Ratio) are platelets parameters provided by automated hematology analyzers (HA) along with the total platelet count (PLT). These parameters measure the size as also the morphology and the degree of anisocytosis of circulating platelets, and they can reflect platelet activity. The aim of this study was to evaluate whether platelet indices can undergo alterations in subjects affected by subclinical and overt clinical hypothyroidism

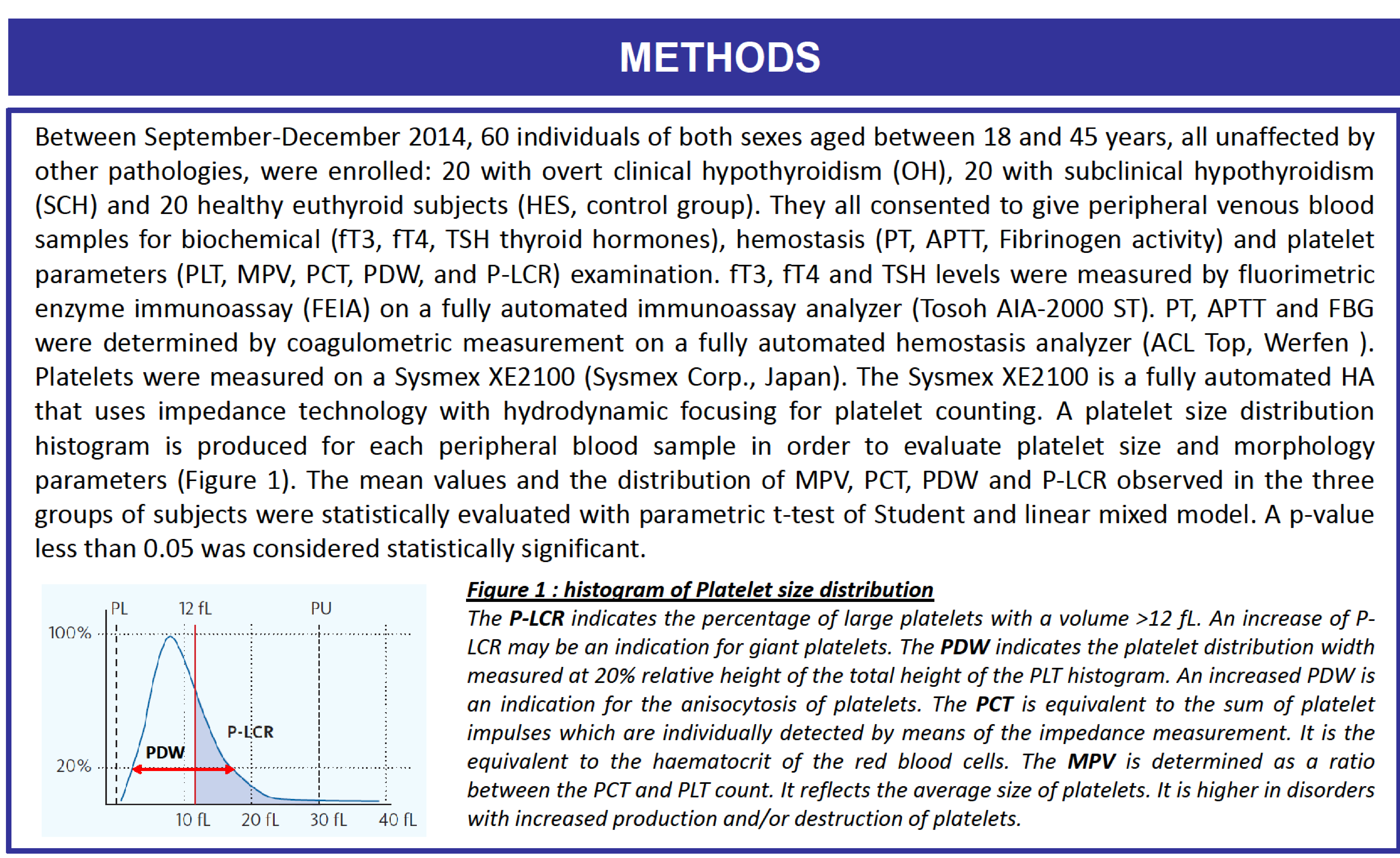

\section{RESULTS}

The mean values of platelet parameters, thyroid function tests and hemostasis parameters observed in the study groups are shown in Table 1. Mean values in subclinical hypothyroid $(\mathrm{SCH})$ and overt hypothyroid patients $(\mathrm{OH})$ were compared with those of healthy subjects (HES). The $p$-value of t-test of Student are shown in Table 2. Platelet counts, P-LCR and PCT were not different between the study groups ( $p>0.05$ ). Compared with the results of the HES group (mean \pm SD: $8.4 \pm 0.93 \mathrm{fL}$ ), MPV values were higher in the $\mathrm{SCH}$ group $(9.0 \pm 0.72 \mathrm{fL}, \mathrm{p}=0.0002)$ and, more significantly, in the $\mathrm{OH}$ group $(9.8 \pm 0.95 \mathrm{fL}, \mathrm{p}<0.0001)$. Similarly, $\mathrm{PDW}$ values were significantly higher in the SCH group $(13.8 \pm 1.26 \mathrm{fL}, \mathrm{p}=0.0016)$ and in the $\mathrm{OH}$ group $(15.2 \pm 2.06 \mathrm{fL}, \mathrm{p}<0001)$ than in the HES group $(12.9 \pm 2.03 \mathrm{fL})$.

The distribution of MPV and PDW in the three study groups are shown in Figure 2 and Figure 3, respectively.

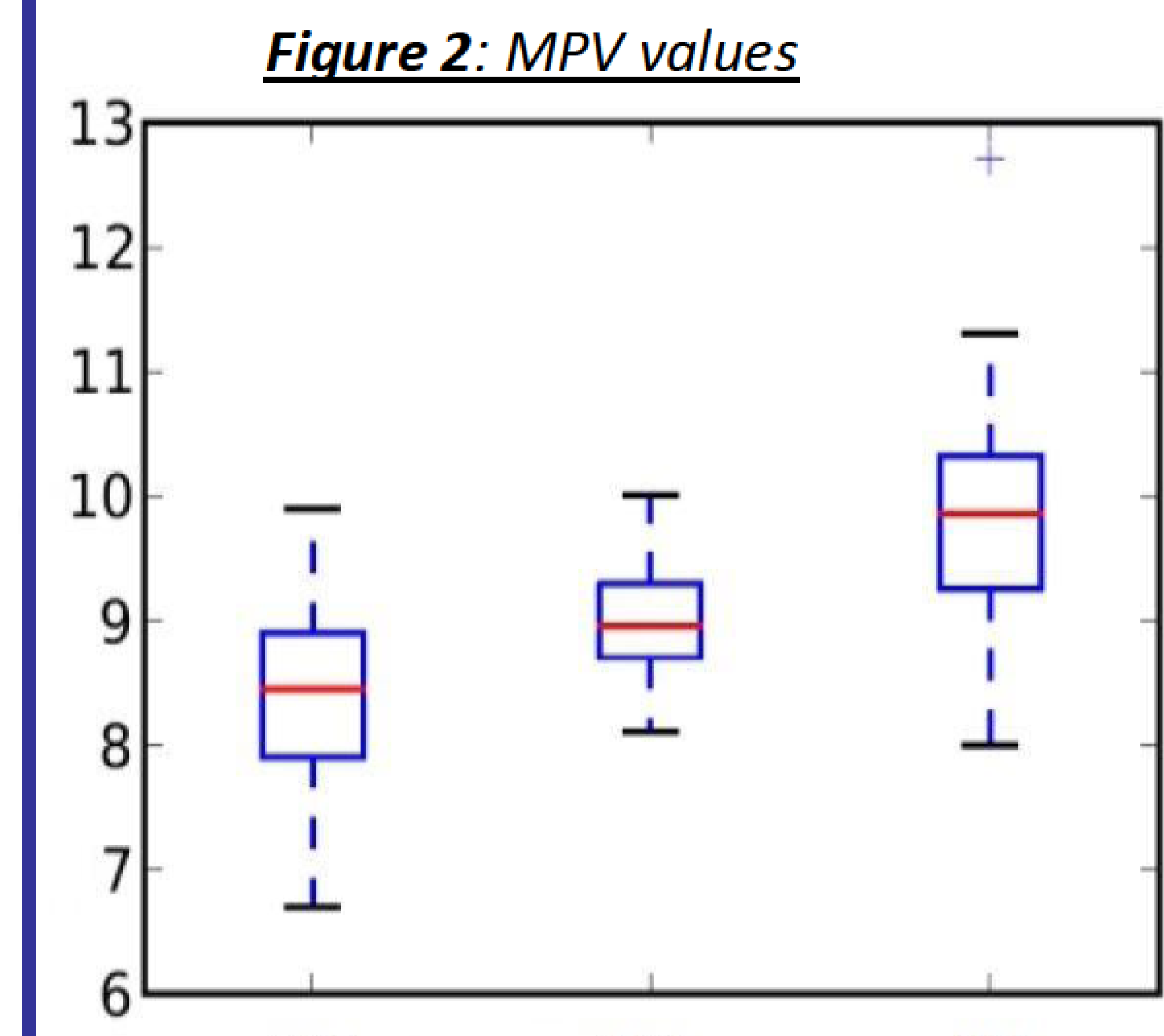

HES

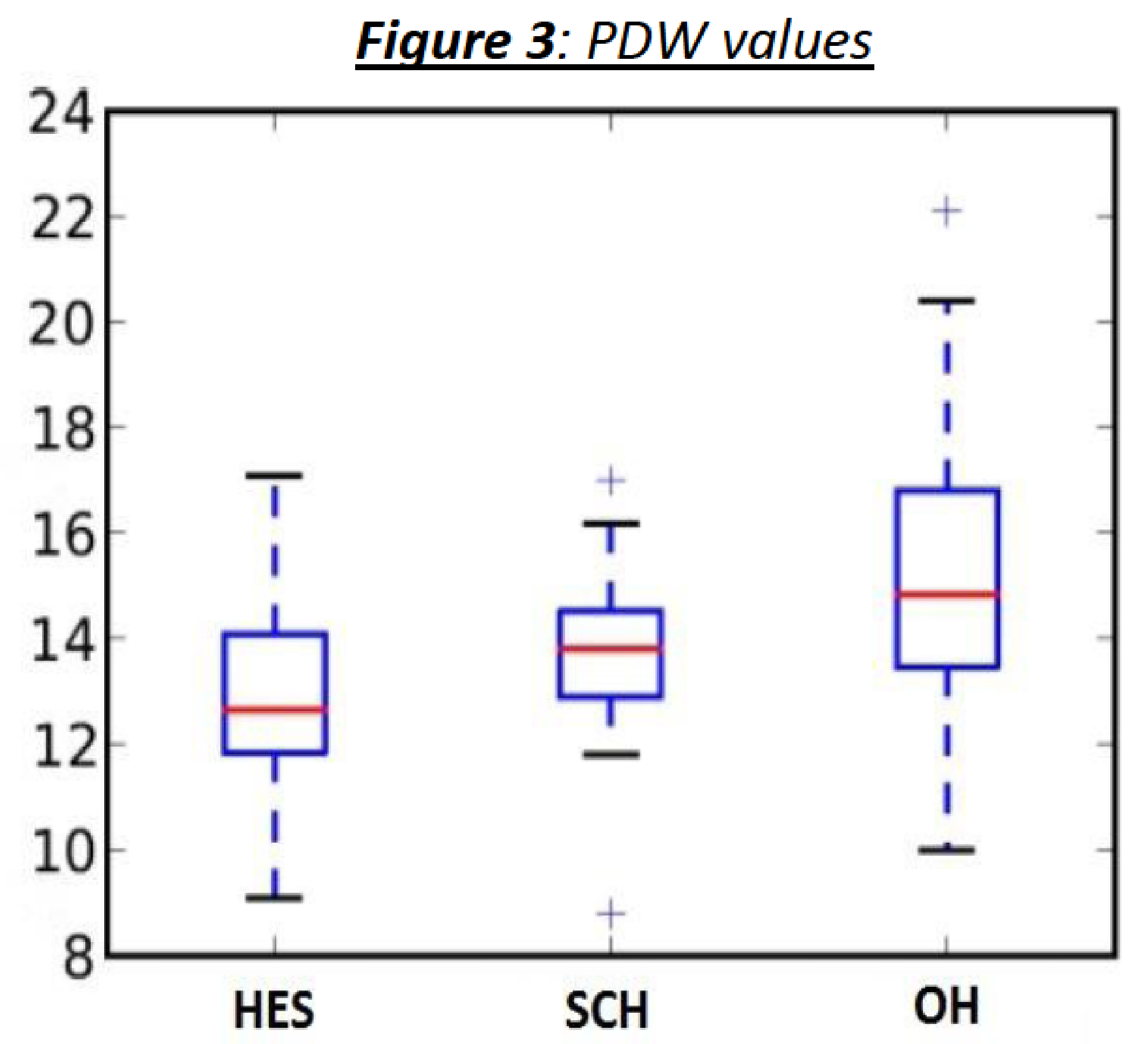

SCH
Table 1: mean values of PLT parameters, thyroid hormones and hemostasis parameters

\begin{tabular}{|c|c|c|c|c|c|c|c|c|c|c|c|}
\hline Group & $\begin{array}{c}\mathrm{PLT} \\
\mathrm{x} 10^{9} / \mathrm{L}\end{array}$ & $\begin{array}{c}\mathrm{MPV} \\
\mathrm{fL}\end{array}$ & $\begin{array}{c}\mathrm{PDW} \\
\mathrm{fL}\end{array}$ & $\begin{array}{c}\mathrm{PCT} \\
\%\end{array}$ & $\begin{array}{c}\mathrm{P}-\mathrm{LCR} \\
\%\end{array}$ & $\begin{array}{c}\mathrm{fT3} \\
\mathrm{fg} / \mathrm{mL}\end{array}$ & $\begin{array}{c}\mathrm{fT} 4 \\
\mathrm{ng} / \mathrm{dL}\end{array}$ & $\begin{array}{c}\text { TSH } \\
\mu \mathrm{IU} / \mathrm{mL}\end{array}$ & $\begin{array}{c}\text { PT } \\
\text { INR }\end{array}$ & $\begin{array}{c}\text { APTT } \\
\text { Ratio }\end{array}$ & $\begin{array}{c}\text { FBG } \\
\mathrm{mg} / \mathrm{dL}\end{array}$ \\
\hline HES & 273 & $\mathbf{8 . 4}$ & 12.9 & 0.28 & 27.2 & 2.92 & 1.23 & 2.61 & 1.00 & 0.98 & 310 \\
\hline SCH & 278 & 9.0 & 13.8 & 0.28 & 28.2 & 2.91 & 1.16 & 6.66 & 1.00 & 1.00 & 309 \\
\hline OH & 277 & 9.8 & 15.2 & 0.30 & 26.7 & 2.12 & 0.81 & 19.91 & 0.76 & 0.98 & 317 \\
\hline
\end{tabular}

Table 2: $p$-values

\begin{tabular}{|c|c|c|c|c|c|c|c|c|c|c|c|}
\hline Group & PLT & MPV & PDW & PCT & P-LCR & fT3 & fT4 & TSH & PT & APTT & FBG \\
\hline $\begin{array}{c}\text { HES vs } \\
\text { SCH }\end{array}$ & 0.69 & 0.0002 & 0.016 & 0.40 & 0.38 & 0.86 & 0.11 & $<0.0001$ & 0.65 & 0.32 & 0.94 \\
\hline $\begin{array}{c}\text { HES vs } \\
\text { OH }\end{array}$ & 0.76 & $<0,0001$ & $<0,0001$ & 0.76 & 0.37 & $<0.0001$ & $<0.001$ & $<0.0001$ & $<0.0001$ & 0.99 & 0.60 \\
\hline
\end{tabular}

\section{CONCLUSIONS}

Hypothyroidism is associated with a worse cardiovascular risk factor profile and leads to progression of atherosclerosis. The results of our study show that MPV and PDW values are significantly higher in patients with subclinical hypothyroidism and, more significantly, in patients with overt hypothyroidism. Even if the mechanisms for increased platelet indices as an indicator of platelet activation in patients with atherosclerosis has not been elucidated, our results suggest (as already reported in previous studies) the usefulness of MPV and PDW indices as a useful and inexpensive markers of platelet activation in the diagnostic work-up of the risk of atherothrombotic complications in patients with subclinical and overt hypothyroidism. However, due to the small sample size of our preliminary study, it is needed to perform further investigations in a larger group of patients in order to assess the clinical usefulness of platelet parameters for the evaluation of cardiovascular risk factor in these patients.

\section{References}

Alev AE. et al: The effects of subclinical Hypotyroidism on platelets parameters. Hematology 14,2 115,2009 Coban E. et al:Platelet activation in subjects with subclinical hypothyroidism Med.Sci.Monit.2007 13(4) 211-4

3. Homoncik M. et al: Altered platelet plug formation in hyperthyroidism and hypothyroidism. J Clin Endocrinol Metab. 2007;92(8):3006-12

4. Kim JH et al: The Mean Platelet volume is positively correlated with serum thyrotropin concentration in a population of healthy subjects and subjects with unsuspected subclinical hypothyroidism.Thyroid 23-1 2013

Ylmaz H et al: Mean platelet volume in patients with subclinical hypothyroidism.Platelet 2011 22(2) 143-7 